\title{
CIUDADES MONUMENTALES Y ENTORNOS PAISAJÍSTICOS. EL CASO DE TRUJILLO Y SU TIERRA (EXTREMADURA, ESPAÑA)
}

\author{
Rafael Mata Olmo \\ Departamento de Geografía. Universidad Autónoma de Madrid \\ Daniel Ferrer Jiménez \\ Departamento de Humanidades. Universidad Carlos III de Madrid
}

\section{RESUMEN}

El texto se ocupa de las relaciones visuales, históricas y funcionales entre ciudades monumentales y sus entornos como paisajes urbanos históricos. Analiza el caso de la ciudad de Trujillo (Extremadura, España). De acuerdo con la definición de paisaje del Convenio Europeo del Paisaje y del Plan Nacional de Paisaje Cultural, se caracteriza y valora el paisaje del entorno urbano y sus relaciones con la ciudad, se establecen objetivos de calidad paisajística y directrices y acciones para la protección, gestión, recualificación y acceso público al paisaje, parte de las cuales se han incorporado al Plan General Municipal de Trujillo, recientemente redactado.

Palabras clave: paisaje, paisaje urbano histórico, ciudades monumentales, urbanismo, ordenación del paisaje.

\section{ABSTRACT}

This text deals with visual, historical and functional relations between monumental cities and their environments as a historic urban landscapes. It analyses the case of the city of Trujillo (Extremadura, Spain). According to the definition of the European Landscape Convention and the National Plan of Cultural Landscape, the text characterizes and assesses the landscape of the urban environment and its relationship with the monumental city, and establishes landscape quality objectives, guidelines and actions for the protection, management, planning and promotion the public access to the landscape, part of which have been incorporated into the Master Plan of Trujillo, recently approved.

Key words: landscape, historic urban landscape, monumental cities, town planning, landscape planning. 
DE LAS VISTAS PANORÁMICAS A LA CONSTRUCCIÓN PAISAJÍSTICA DEL ENTORNO. El CASO De Trujillo

Los conjuntos urbanos históricos guardan una estrecha y múltiple relación con sus entornos territoriales. Se trata, en primera instancia, de una relación visual, sobre todo cuando -como es frecuente- dichos conjuntos se emplazan sobre altozanos o a los pies de cerros y promontorios. Son las visiones externas y panorámicas de la ciudad, la «imagen de conjunto» (Zoido Naranjo, 2012), posibles cuando, como en el caso de Trujillo que nos ocupa, el núcleo es de modestas dimensiones y aparece topográficamente destacado. La representación de estas vistas urbanas cuenta con un amplio recorrido histórico, materializado en numerosas manifestaciones artísticas. Como ha señalado Santiago Pardo, «estuvieron ligadas en su origen a la descripción fiel de lugares, para lo que se recurría a precisas técnicas de restitución métrica. Las primeras obras, a cargo de autores como Anton van den Wyngaerde o Joris Hoefnagel, son resultado del empeño común de pintores y geógrafos por mostrar el mundo con fidelidad, encuadrándose por ello en el ámbito de la corografía» (Pardo García, 2010: 37$)^{1}$.

Pero junto a las relaciones visuales existen vínculos profundos, históricos y presentes, de naturaleza funcional, que explican parte de las características y evolución de las viejas ciudades patrimoniales y la propia organización del espacio sobre el que aquellas han ejercido su influencia económica, social y jurisdiccional.

Una aproximación a estas relaciones de «coevolución» desde un enfoque paisajístico renovado como el que preconiza el Convenio Europeo del Paisaje (Consejo de Europa, 2000) y desde la propia tradición geográfica en el estudio de la ciudad (Quirós Linares, 2004), permite leer tales relaciones materializadas en el paisaje y en sus representaciones sociales, y reconocer valores patrimoniales en los vínculos históricos del conjunto urbano y su tierra. De esta forma, la interpretación de la ciudad integrada en el paisaje se enriquece como experiencia patrimonial, y a la vez, el entorno, más o menos lejano según los casos, encuentra en la ciudad claves explicativas de su organización, morfología y funcionamiento pasado y actual. Las oligarquías radicadas históricamente en ciudades y agrovillas han modelado y gestionado secularmente los paisajes de sus áreas de influencia, y las rentas de sus campos han quedado en parte materializadas en edificios y espacios públicos de valor patrimonial, que configuran el paisaje urbano interior.

Un enfoque como éste, que sigue de cerca también los planteamientos más recientes de la UNESCO en su «Recomendación sobre el paisaje urbano

1. Del mismo autor, su tesis doctoral inédita (Pardo García, 2015) y Pardo García y Mérida Rodríguez (2015). 
histórico», de la 36. ${ }^{a}$ Reunión (10 de noviembre de 2011), o el documento británico «Seeing the History in the View» (English Heritage, 2011), es el que inspira el estudio paisajístico de algunos casos de ciudades históricas y sus entornos dentro del proyecto $\mathrm{I}+\mathrm{D}+\mathrm{i}$ «Paisajes patrimoniales de España» (CSO2012-39564-C07-03). Uno de los elegidos fue precisamente el de Trujillo. En este terreno, la evolución de los objetivos de conservación y gestión del bien patrimonial ligado a los conjuntos urbanos ha evolucionado, como es sabido, desde la protección de agrupaciones de edificios monumentales de fines de los años sesenta del siglo Xx, pasando por la salvaguarda de los conjuntos y las ciudades históricas de la Recomendación de Nairobi (1976) y la Carta de Washington (1987), hasta el Memorándum de Viena (2005) sobre «Patrimonio mundial y arquitectura contemporánea-Cómo gestionar los paisajes urbanos históricos» y los Principios de La Valetta de 2011. Como resultado de ese proceso, la citada «Recomendación sobre el paisaje urbano histórico» es en la actualidad, con carácter a nuestro juicio más metodológico que conceptual y sin perjuicio de sus problemas de interpretación y aplicación (Lalana Soto, 2011), la herramienta que pretende mejorar sustancialmente la conservación y gestión del patrimonio urbano de acuerdo con la complejidad ambiental, territorial, cultural y perceptiva que implica la noción de paisaje ligada a la ciudad histórica, integrándola en su contexto territorial más amplio (Ibanez, Merlot y Roux, 2013).

Hace algún tiempo, los autores de este texto, investigadores del proyecto citado, participaron en algunas sesiones del Seminario Permanente de Paisaje y Territorio de Trujillo, nacido en 2011 como «un proyecto de integración entre la ciudad de Trujillo, su paisaje y territorio». Se trata de una iniciativa de ADENEX y de la Fundación Xavier de Salas (Convento de la Coria, Trujillo), un foro singular en el panorama de las iniciativas de la sociedad civil y el paisaje a escala local en España, y en el que, entre otros actores, participa el Ayuntamiento. El Seminario surge como un intento de las entidades mencionadas y de personas a título individual por «abordar la convergencia de miradas y enfoques en torno a la relación entre el territorio y su paisaje en el entorno de la ciudad de Trujillo» (http://paisajetrujillo.blogspot.com.es/).

Junto a los notables y reconocidos valores del paisaje de Trujillo y su berrocal (Alvarado Corrales, 2013), y de los elementos y estructuras paisajísticas que lo integran (Campesino Fernández, 1991), han preocupado en el Seminario las muestras de deterioro y los impactos de determinadas implantaciones en el espacio granítico, así como las perspectivas de cambio de uso del suelo contrarios a esos valores en un contexto de falta de planeamiento urbanístico actualizado (solo dispone Trujillo de Normas Subsidiarias, revisadas en el año 2000), con una importante extensión de terrenos sin ninguna protección en el entorno de la ciudad. Fruto de esa situación «Trujillo y el berrocal circundante» fueron 
incluidos recientemente en la Lista Roja de Hispania Nostra ${ }^{2}$, definiéndose el «carácter del riesgo» en los siguientes términos:

El principal problema derivado de la actual situación urbanística reside en que si bien una parte del berrocal sí tiene protección, otra, la inmediata a la autovía, muy cercana a la ciudad y que afecta enormemente a la totalidad del paisaje percibido desde las cotas más elevadas, no tiene protección alguna, pues se trata de suelo inadecuado para el desarrollo urbano, lo que equivale a un suelo no urbanizable común. Todo esto se concreta en que con la calificación actual en esta franja se puede ubicar todo tipo de industrias y usos turísticos permanentes. Existe el peligro inmediato de la ejecución de un proyecto de 58 apartahoteles, campo de golf, spa y centro de convenciones en mitad del berrocal, al norte de la ciudad (...). Todo ello significará la pérdida de una de las señas de identidad principales de la ciudad: la fusión de su patrimonio arquitectónico con su medio natural y paisajístico que hacen de ella, junto con Ávila o Cáceres, una de las ciudades más espectaculares de la Edad Media y Moderna española. (http:// listarojapatrimonio.org/ficha/trujillo/)

En ese marco, el Ayuntamiento de Trujillo puso en marcha a comienzos de 2013 los trabajos del primer Plan General Municipal (PGM), que desde abril de 2015 cuenta con Aprobación inicial. El consistorio entiende el PGM como «instrumento de ordenación del territorio y planeamiento urbanístico, en el cual el paisaje debe ser incluido como uno de los elementos de mayor valor y potencialidad del municipio y por tanto debe ser contemplado de forma específica dentro del planeamiento a través de una 'estrategia de paisaje'. Esta estrategia debe traducirse en una serie de directrices de ordenación, actuación y gestión del paisaje que garanticen la protección y puesta en valor de tan importante activo cultural y ambiental colectivo» ${ }^{3}$.

A lo largo de 2014 se llevaron a cabo los trabajos del denominado «Estudio y Estrategia de paisaje de Trujillo y su Tierra. Directrices paisajísticas para el Plan General Municipal de Trujillo» ${ }^{4}$, que forma parte de la documentación del PGM. Una parte significativa de sus directrices y acciones, como se verá más adelante, se han incorporado a la Memoria Justificativa y a la Normativa del Plan.

Partiendo, pues, de una investigación básica sobre paisajes patrimoniales en los términos que se han enunciado al comienzo, el «Estudio y Estrategia de paisaje» ha pretendido aportar, por una parte, criterios de distinto alcance jurídico al modelo territorial definido por el PGM, dentro de los límites que permite

2. La Lista Roja del Patrimonio es una iniciativa de la Asociación Hispania Nostra. Esta Lista recoge elementos del patrimonio histórico español que se encuentren sometidos a riesgo de desaparición, destrucción o alteración esencial de sus valores.

3. Exposición de Motivos del Convenio Específico de Colaboración entre la Universidad Autónoma de Madrid y el Ayuntamiento de Trujillo (marzo de 2014).

4. Ha recibido el I Premio de Urbanismo y Ordenación Territorial de la Comunidad Autónoma de Extremadura (2015), en la modalidad «mejor planificación urbanística o territorial». 

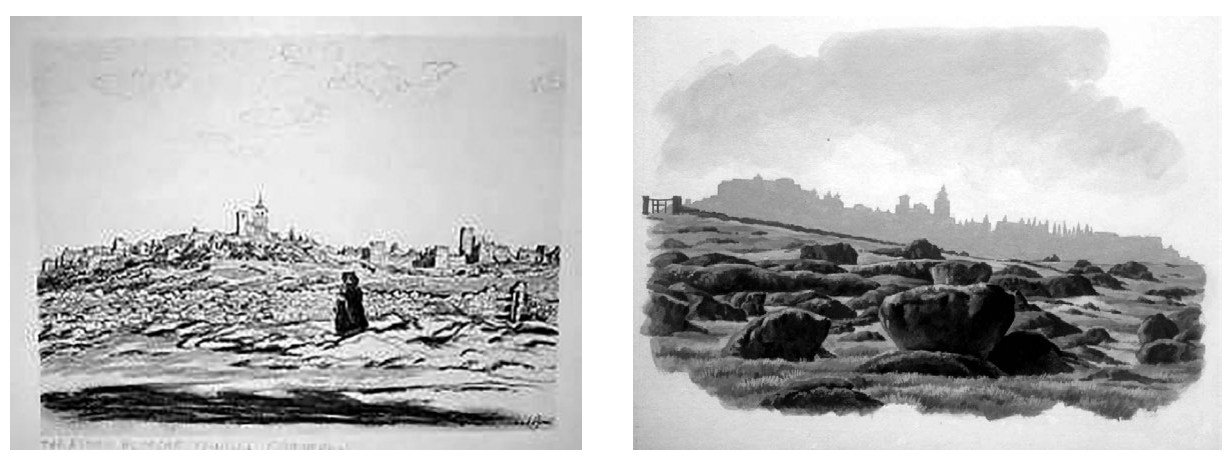

Figuras 1 (izquierda) y 2 (derecha). «The Ruined Alcazar», grabado del pintor escocés Bone Muirhead, incluido en la obra Old Spain, de Gertrude Muirhead (1936) y acuarela «El Berrocal y Trujillo», de Adán Ferrer (2015)

un instrumento urbanístico de estas características. Sin embargo, una estrategia de paisaje tiene un horizonte y pretensiones más amplias que las que marca el planeamiento municipal. Por ese motivo el estudio abordado no se restringe a los límites del extenso término trujillano, sino que se ha ampliado a otros pequeños municipios contiguos (Aldea del Obispo, Plasenzuela, La Cumbre y Santa Marta de Magasca), que integran con él una gran pieza de territorio geohistórico en la penillanura extremeña entre los ríos Almonte y Tamuja.

Además, la Estrategia que acompaña al Estudio, con las directrices y acciones que se presentan más adelante, no se restringe al ámbito disciplinar del planeamiento urbanístico, sino que incluye iniciativas para la activación del patrimonio paisajístico del alfoz trujillano, entendiéndolo como recurso de desarrollo territorial ligado al nodo patrimonial de la ciudad de Trujillo y a un destino de turismo cultural y de naturaleza relativamente acreditado, que pretende fortalecerse y cualificarse (véase, en esa línea, Troitiño Vinuesa y Troitiño Torralba, 2011). Por encima de todo, el Estudio de paisaje, sea cual sea el grado de implementación de la Estrategia, cumple también una tarea fundamental establecida por el Convenio de Florencia: contribuir, a escala local y comarcal, a la caracterización y cualificación del paisaje, y a la educación, divulgación y sensibilización en sus valores. El proceso de consulta pública y participación social que ha acompanado al desarrollo de los trabajos ha sido una buena prueba de ello.

\section{LA CARACTERIZACIÓN DEL PAISAJE COMO PARTE DE LA ESTRATEGIA}

\section{Enfoque y método del Estudio}

E1 Estudio entiende el paisaje, de acuerdo con distintas tradiciones disciplinares contemporáneas y con la definición establecida por el Convenio Europeo del Paisaje (Consejo de Europa, Florencia, 2000), como «cualquier parte del 
territorio, tal y como la percibe la población, cuyo carácter sea el resultado de la acción y la interacción de factores naturales y/o humanos» (traducción del Instrumento de Ratificación del Convenio Europeo del Paisaje, BOE de 5 de febrero de 2008). El paisaje es, pues, en primera instancia, el carácter del territorio - de cada territorio-, es decir, un conjunto de rasgos y cualidades que lo identifican y diferencian de otros. El carácter expresa además, en ámbitos históricamente construidos como el de la tierra trujillana, las huellas de etapas pasadas y es el resultado en su configuración formal, en su funcionamiento y evolución, y en sus representaciones sociales, de las relaciones entre una naturaleza siempre transformada y modos cambiantes de aprovechar y habitar el territorio a lo largo del tiempo (Mata Olmo, 2008).

Pero el paisaje del que se ocupa este estudio no es sólo el «carácter del territorio», con todo lo que eso implica ya desde el punto de vista de su cualificación y de la acción pública. El paisaje es el «carácter» de cada porción del territorio «percibido por la población», una percepción multisensorial -en primera instancia, visual-, que incorpora procesos mentales más complejos de comprensión, identificación y aprecio estético, no sólo por sus cualidades formales, sino -como afirma Venturi Ferriolo (1999)- por los valores naturales y culturales que alberga y por la historia que cada paisaje es capaz de contar.

Desde esta concepción, la tarea de caracterización y valoración de la diversidad paisajística del término municipal de Trujillo y de su tierra más próxima, de la que la ciudad histórica no puede desligarse, se ha organizado en torno a tres grandes capítulos, que a continuación se presentan. Para su elaboración se han seguido de cerca las propuestas metodológicas de Landscape Character Assessment (LCA) (Scottish Natural Heritage-The Countryside Agency -hoy English Nature-, 2002; 2014) y de los atlas franceses de paisaje, de escala mayoritariamente departamental o regional (Brunet-Vink, 2004), así como los estudios de caracterización del paisaje llevados a cabo en España en el último decenio; entre estos últimos, en concreto, los catálogos del Observatori del Paisatge de Cataluña (Nogué y Sala, 2006), los realizados en la Comunidad Valenciana en desarrollo de su Ley de Ordenación del Territorio y Protección del Paisaje, de 2004 (escasamente difundidos) y los del Centro de Estudios Paisaje y Territorio de la Junta de Andalucía (VV.AA, 2010), particularmente el realizado sobre el entorno del núcleo urbano de Constantina (Zoido Naranjo, dir., 2013). De interés ha resultado también la metodología paisajística del Programa Territorio y Patrimonio, de la Fundación Botín, dirigido por José María Ballester, del que existen distintas publicaciones, y que tiene el interés de abordar el paisaje como síntesis patrimonial del territorio y como recurso de desarrollo territorial, con una visión proactiva que se proyecta en estrategias y directrices como las que plantea el estudio de Trujillo (Meer Lecha-Marzo, coord.., 2010; Mata Olmo, 2010).

Igualmente, el documento asume la definición de «paisaje cultural» adoptada por el Plan Nacional de Paisaje Cultural (PNPC) (MECD-IPCE, 2012) y 
los principios y objetivos que lo fundamentan, hasta el punto de que en el capítulo de directrices propone para el paisaje del Berrocal de Trujillo una figura de protección integral que coordine iniciativas del campo de la protección de la naturaleza y del patrimonio cultural, en torno a un Plan Director como el que establece el citado PNPC.

\section{Elementos y procesos de modelado del paisaje. Naturaleza transformada y construcción histórica}

En la tarea de identificación y análisis del carácter del paisaje, se ha procedido en primer lugar al estudio de los componentes y procesos constitutivos del paisaje y, a continuación, a concretar la diversidad paisajística del territorio en tipos y unidades de paisaje, que resultan de una particular articulación y organización de los componentes citados. Se trata de un estudio intencionado, con un objetivo claramente paisajístico, interesado por el reconocimiento y la interpretación de los caracteres estructurales del paisaje, es decir, de aquellos elementos dotados de relativa estabilidad y permanencia, y expresivos de la identidad paisajística de los lugares. Para ello, junto a tratamiento de diverso material cartográfico, estadístico y archivístico, ha resultado fundamental el trabajo de campo a lo largo de doce campañas de entre dos y cuatro días llevadas a cabo entre los meses de marzo y julio de 2014, y que han alimentado también el proceso participación social, que se comentará más adelante. Sintéticamente, la atención se ha centrado en los siguientes aspectos:

- Un clima mediterráneo moderadamente continentalizado, de inviernos frescos y húmedos, y veranos secos y cálidos, como base del sistema agroganadero tradicional y de los contrastes estacionales del paisaje.

- La diversidad geomorfológica como soporte físico del paisaje: las grandes unidades morfoestructurales, las geoformas locales y los microrrelieves, incidiendo, por una parte, en el rico repertorio de formas graníticas del berrocal, asiento y cantera del Trujillo monumental y de la organización humana de su ejido concejil hasta fines del siglo XIX; y, por otra, los relieves de la penillanura pizarreña, en especial, los «llanos», riberos y angosturas, y pequeñas sierras cuarcíticas.

- El decisivo papel de las aguas superficiales en el modelado y la percepción del paisaje, y en la construcción y uso de huertos, aldeas y arrabales de Trujillo.

- La dimensión y los valores agroecológicos del paisaje, con especial atención a las distintas tipologías de dehesa como hábitats de interés, y a los corredores ecológicos fluviales.

- La construcción histórica del paisaje 
Una mención especial merece el último de los asuntos citados, el de la construcción histórica del paisaje, pues es el que permite establecer de forma más clara las relaciones de co-evolución entre Trujillo y su tierra en la interpretación material y simbólica del paisaje. Trabajando con fuentes inéditas del Archivo Municipal de Trujillo y la bibliografía disponible, el Estudio contribuye -aun siendo consciente de cuánto queda por hacer- a desvelar un proceso secular que modela y remodela los paisajes trujillanos y que puede ser contemplado en la actualidad a través de las formas y funciones que los paisajes ofrecen a los sentidos como un magno patrimonio heredado. Dicho capítulo se ha centrado en los siguientes asuntos:

- El largo proceso de apropiación y ocupación de la tierra, con antecedentes prehistóricos, de claras raíces medievales que ligan a la ciudad con su alfoz y que resulta legible en el paisaje actual.

- El contraste, de fuerte significado morfológico, funcional y simbólico, del latifundio adehesado con los ruedos, huertos y suertes de jornaleros y yunteros.

- La domesticación y el diverso aprovechamiento agrosilvopastoril del monte mediterráneo primigenio, materializado en distintas formas y estructuras de dehesas y en el mosaico vegetal y de aprovechamientos del parcelado berrocal.

- Las vías pecuarias, elemento vertebrador de la morfología y funcionamiento de pastaderos, dehesas y montes, y vía hoy de acceso público al paisaje.

- Un poblamiento histórico, jerarquizado e integrado en el paisaje, armónico con las formas tradicionales de uso de los recursos agropecuarios y la geopolítica bajomedieval de la «frontera» extremeña.

Aunque con importantes antecedentes prehistóricos y huellas de la romanización y la ocupación musulmana, las raíces medievales de la conquista cristiana son las que han dejado una impronta mayor en el paisaje actual, visible tanto en el sistema de poblamiento como en las tramas rurales (Sánchez Rubio, 1993). Tales raíces, transformadas con el paso de los siglos, aparecen plenamente consolidadas a fines del Antiguo Régimen, como muestra la rica información del catastro del Marqués de Ensenada de mediados del siglo XVIII y otras fuentes coetáneas.

La gran propiedad agroganadera, materializada en diversos tipos de dehesa, de titularidad nobiliaria, hidalga y eclesiástica, junto al importante papel de los Baldíos y Propios de Trujillo en su término privativo y su extenso alfoz, hasta los confines de Las Villuercas por el sur, mantendrá desde el segundo tercio del siglo XIX hasta la actualidad su estructura y configuración latifundista, por encima de los muy importantes cambios de titularidad ocasionados 
por la disolución del régimen señorial, las desamortizaciones eclesiástica y civil -ambas con gran incidencia en Trujillo-, y por la quiebra de algunas casas nobiliarias con patrimonio rústico y urbano en la comarca (Rubio Garlito, 1986; Sánchez Marroyo, 1993).

Un parcelario de grandes dehesas y montes, pastaderos y labrados, con amplios cortijos, algunos de notable fábrica y valor patrimonial en forma de «palacios» (Maldonado Escribano, 2006), remozados o de nueva planta en la segunda mitad del XIX, fruto de los trasiegos de propiedad, constituyen la prolongada herencia y la trama fundiaria básica de los paisajes trujillanos. A esas grandes piezas históricas de propiedad se asocian construcciones rurales, caminos y cercas, y un rico mosaico de coberturas vegetales y aprovechamientos ganaderos organizados en torno a la unidad básica de explotación, la dehesa, de puro pasto en unos casos, de arbolado, labor y pastos en las dehesas por antonomasia.

Pero el paisaje de la tierra trujillana expresa también en la morfología rural, la particular forma de poblar de las huertas y las aldeas -aguijones, colgadizos y agregados en su origen bajomedieval; villas algunas de ellas con el paso del tiempo-. Es el otro paisaje, el de los menesterosos, de braceros y modestos yunteros, sin el que no se comprende el paisaje adehesado, consagrado hoy por sus innegables valores ecológicos, culturales y estéticos, pero trabajado y modelado durante siglos por quienes vivían en las huertas y en los pueblos, lugares de fuerte carácter, contrapuesto al de la ciudad encumbrada, sus edificios monumentales y sus grandes patrimonios rústicos. Por eso adquieren relevancia desde la perspectiva integradora y cultural del paisaje estas configuraciones paisajísticas ligadas a los más humildes, a las suertes y hazas de los ruedos de las aldeas y pueblos, y a las huertas muradas de Ánimas, la Magdalena y Belén, en el corazón del berrocal trujillano, o el Pago de San Clemente, todos ellos paisajes del trabajo duro, la explotación y el sufrimiento.

\section{Sobre la organización visual del paisaje. Potencialidad y fragilidad}

Junto a las principales estructuras y procesos modeladores del paisaje, el Estudio se ocupa de las condiciones de visibilidad general del territorio como base de la dimensión perceptiva del paisaje. Se aborda concretamente la organización escénica del espacio, atendiendo a sus principales hitos, a la configuración de cuencas visuales y su fragilidad, particularmente las de las distintas caras de la fachada urbana de Trujillo y su intervisibilidad con el entorno, así como las condiciones de acceso a la contemplación y lectura del paisaje a través de miradores, institucionalizados o potenciales, y de itinerarios paisajísticos de primer nivel.

Los rasgos más significativos de la organización visual del paisaje en Trujillo y su comarca se resumen en los cinco siguientes (figura 3): 

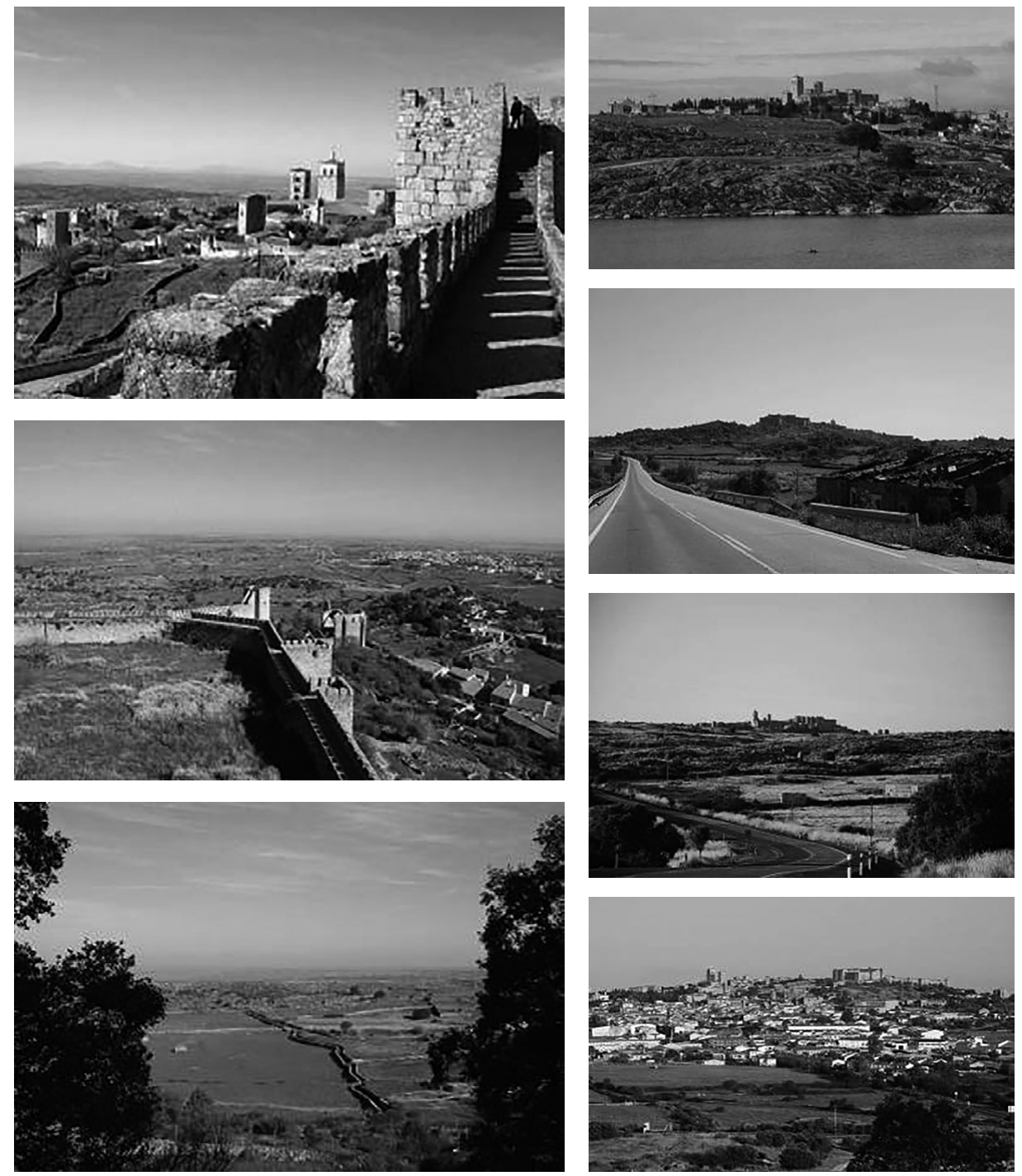

Figura 3. Vistas panorámicas desde el Castillo de Trujillo y Santa María de La Coria (izquierda), y desde el entorno hacia el Castillo y la Villa (derecha). Fotografías de los autores.

- Protagonismo de la alcazaba-castillo y la Villa vieja de Trujillo enriscada en el berrocal, hito y atalaya patrimonial de méritos sobresalientes en la penillanura extremeña y en el suroeste ibérico.

- Combinación de grandes panorámicas de escalas comarcal y regional, y de primeros planos y planos medios para la interpretación de componentes y procesos del paisaje. 
- Abundancia de hitos y atalayas sobre resaltes topográficos de la penillanura y sierra de los Lagares, miradores de segundo orden.

- Secuencias visuales de amplios horizontes a través del viario rodado, con sucesión de umbrales panorámicos y suaves vaguadas.

- Cuencas visuales claramente acotadas y contrastadas de los riberos, piezas de diversidad visual y perceptiva de primer nivel.

El espacio municipal de Trujillo y de los pueblos de su Tierra cuenta, pues, con un valioso recurso paisajístico visual, de elevada fragilidad, que debe ser adecuadamente ordenado y activado. Es significativo que ya en el siglo XviII, con motivo de la solicitud de licencia por parte de la abadesa y religiosas del convento de San Francisco el Real de la Puerta de la Coria para la reedificación de la torre del Postigo y lienzo de la muralla contiguo, se planteara «fabricar en ella un mirador para más extensión y divertimiento». Reproducimos por su interés el texto procedente del AMT.

Por parte de las Señoras abadesa, y religiosas del convento de San Francisco el Real de la Puerta de Coria de esta ciudad se la ha representado que inmediato a la huerta del convento, al sitio que dicen el Espolón del Postigo está un pedazo de muralla y al fin de ella una torre alta que por se hallarse mucha parte arruinada (...) por ella subían algunas personas facilitando por este medio poder entrar en dicha huerta y violar la clausura del referido convento, tomó la comunidad la providencia de que se reedificase dicha torre y parte de muralla para que quedando con suficiente altura se evitasen los perjuicios que de mantenerse con dichas ruinas podían resultar. Suplicando a la ciudad se sirva conceder licencia a dicho convento para poder sus religiosas tener uso y paso desde dicha huerta, por dicha muralla hasta dicha torre y fabricar en ella un mirador para más extensión y divertimiento, mediante que para poderlo hacer se les ha concedido licencia por el Ilmo. Señor Obispo de Plasencia (...).

Fuente: Actas del Concejo de 31 de mayo de 1736, folio 55vto. (destacado de los autores).

\section{Unidades y tipos de paisaje como expresión sintética de la diversidad paisajística de la Tierra de Trujillo}

El estudio de la diversidad paisajística de un territorio se concreta habitualmente en las denominadas unidades de paisaje. Se trata de un concepto de uso frecuente, cuya definición y tratamiento metodológico no está, sin embargo, definitivamente cerrado. La concepción integradora de paisaje del Convenio de Florencia y numerosas experiencias de estudio y ordenación paisajística de escala territorial conducen a un concepto de unidad de paisaje que pretende expresar el carácter de cada paisaje a una determinada escala. Una unidad de paisaje sería, pues, aquella combinación de elementos que genera una fisonomía 
Cuadro 1. Tipos de paisaje de la Tierra de Trujillo

\begin{tabular}{|l|r|r|}
\hline \multicolumn{1}{|c|}{ TIPOS DE PAISAJE DE LA TIERRA DE TRUJILLO } & $\begin{array}{c}\text { Superficie } \\
(\mathbf{K m} \mathbf{2})\end{array}$ & $\begin{array}{c}\text { Porcentaje } \\
(\mathbf{\%})\end{array}$ \\
\hline 1. Arrabales, cercas y huertas del berrocal de Trujillo & 7 & 0,80 \\
\hline 2. Berrocales de la Tierra de Trujillo & 121 & 14,08 \\
\hline 3. Ruedos de los colgadizos de Trujillo & 24 & 2,80 \\
\hline 4. Llanos del noroeste de Trujillo & 161 & 18,70 \\
\hline 5. Dehesas trujillanas & 122 & 14,20 \\
\hline 6. Montes y dehesas de las vertientes del Almonte y el Tamuja & 223 & 25,88 \\
\hline 7. Sierra de los Lagares (Pago de San Clemente) & 7 & 0,82 \\
\hline 8. Pastizales y labrados del entorno de los berrocales de Trujillo y \\
Plasenzuela-La Cumbre & 145 & 16,86 \\
\hline 9. Riberos & 33 & 3,80 \\
\hline 10.Labrados de La Cumbre & 15 & 1,79 \\
\hline 11. Viñedos de la Dehesa de la Torrecilla & 2 & 0,22 \\
\hline TOTAL & $\mathbf{8 6 1}$ & $\mathbf{1 0 0 , 0 0}$ \\
\hline
\end{tabular}

Elaboración propia a partir del SIG de paisaje de Trujillo y su Tierra

particular, una organización morfológica diferenciada y diferenciable que hace a una parte del territorio distinta de otra.

La diversidad de configuraciones paisajísticas de los $860 \mathrm{~km}^{2}$ del espacio analizado, atendiendo a su carácter y visibilidad, se expresa en un total de 31 paisajes. Esas piezas básicas se han agrupado en 11 «tipos de paisaje» (cuadro 1). Los tipos están integrados por unidades paisajísticas que presentan importantes rasgos compartidos, tango geoecológicos como culturales. Sin perjuicio de que las unidades de paisaje constituyen las piezas básicas de la diversidad paisajística comarcal, se ha llegado a la conclusión de que, en el caso de Trujillo, los principales rasgos distintivos del paisaje, tanto naturales como históricoculturales y productivos, se manifiestan en el nivel de los tipos; las unidades se han diferenciado más por sus particulares límites visuales, por el hecho de que son realidades geográficas discontinuas dentro del tipo de paisaje o porque presentan valores matizadamente distintos. Por otra parte, se ha considerado también, como se expondrá más adelante, que el ámbito espacial de los tipos de paisaje resulta más adecuado para establecer correspondencias y criterios para las determinaciones del Plan General Municipal en materia de clasificación y ordenación de suelos no urbanizables protegidos. La caracterización de cada tipo de paisaje y de las unidades que lo integran se ha llevado a cabo en una ficha que incluye los siguientes apartados: 
- Rasgos distintivos del tipo de paisaje.

- Elementos naturales constitutivos del paisaje.

- Elementos humanos constitutivos del paisaje.

- Evolución histórica, cambios y tendencias recientes.

- Visión del paisaje: observación y acceso público.

- Fortalezas y debilidades.

- Unidades de paisaje del tipo: carácter, singularidad y valoración.

- Fotografías, imágenes, mapas y croquis.

Del conocimiento a la acción. Directrices paisajísticas Para el PGM de TrujILlo

\section{Contribución de la participación social}

La participación social, desde las iniciativas de consulta sobre caracterización, uso y cualificación del paisaje, hasta la toma de decisiones, constituye un aspecto esencial de los postulados del Convenio de Florencia. Si el CEP insiste en esta cuestión -dicen Prieur y Durousseau- es para traducir jurídicamente la especificidad del 'paisaje' del mejor modo posible. El paisaje no existe más que a través de lo que se ve. Una política que implicase exclusivamente a los expertos y a la administración, produciría un paisaje soportado por la gente, al igual que en el pasado pudo ser producido por y para una élite. La democratización del paisaje no está sólo vinculada al nuevo campo de acción introducido por la Convención de Florencia, sino que se expresa a través de esta apropiación colectiva e individual de todos los paisajes, que necesitan para su transformación, para el seguimiento de su evolución y para la prevención de su destrucción desconsiderada, una participación directa de todos en todas las fases de decisión» (Prieur y Durousseau, 2004: 16).

Sintéticamente, la experiencia de participación social en el caso de Trujillo ha resultado positiva tanto por el contexto y el modo en el que se ha desarrollado, como por lo que ha aportado al documento en su conjunto. En cualquier caso, la participación en paisaje, como en otros ámbitos, es un proceso abierto y continuo, y no puede reducirse a un evento o conjunto de eventos, sino al seguimiento de un proceso que debiera conducir de la participación a la implicación ciudadana en la defensa y activación de los valores del paisaje como patrimonio común y recurso de desarrollo territorial. Un aspecto contextual favorable en cuanto a participación a lo largo de los trabajos, antes incluso de su inicio ha sido la existencia del ya mencionado Seminario Permanente sobre Paisaje, al que se han incorporado los autores del Estudio y del que han recibido informalmente sensaciones, opiniones y contribuciones muy valiosas. 
Por otra parte, aunque el Estudio y sus directrices constituyen un documento de «expertos», el trabajo de campo, en el terreno y con la gente, a lo largo, como se ha dicho, de doce campañas, ha sido fundamental como un modo de «participación pública informal». De las diez entrevistas en profundidad a una serie de actores locales (cuatro vecinos «implicados» de los pueblos de Belén y Huertas de Ánimas; un gran propietario-empresario de un grupo de dehesas de una sociedad familiar; un técnico ambiental comarcal; un gran operador cinegético; dos estudiosos locales), cinco han sido realizadas en el campo, recorriendo y valorando paisajes concretos, un método muy rico para recabar información, pero también críticas, aspiraciones y propuestas. Además, estas entrevistas han intentado cubrir, hasta donde ha sido posible, algunas ausencias en el proceso articulado de participación ciudadana «Repensar el Paisaje de Trujillo», llevado a cabo por Gea 21 (2014). Siguiendo la metodología European Awareness Scenario Workshop (EASW), el taller «Repensar el Paisaje de Trujillo», ha constituido la plataforma de expresión de sentimientos y aspiraciones paisajísticas de una parte de la población trujillana, en coordinación estrecha con la realización del Estudio, y sobre los asuntos siguientes:

- El carácter y la identidad del paisaje : explorar y compartir las imágenes, los recuerdos y los lugares más utilizados en la actualidad con relación al paisaje de Trujillo

- Definición de escenarios de futuro: la visión del futuro del paisaje y el territorio de Trujillo más optimista y deseada, y también la más pesimista o temida.

- Las aspiraciones paisajísticas y las propuestas para caminar hacia el mejor escenario de futuro o evitar los peores temores de declive y deterioro del paisaje trujillano.

De los «objetivos de calidad paisajistica» a las directrices de paisaje del PGM

Sobre la base de conocimiento experto del paisaje, impregnado de vivencias locales y de aspiraciones colectivas, la Estrategia, de acuerdo con el CEP, define los «Objetivos de Calidad Paisajística de Trujillo» como nexo de unión entre el estudio de caracterización y cualificación -el que podría denominarse «catálogo» de los paisajes de Trujillo, siguiendo la terminología acuñada por el Observatori del Paisatge de Cataluña- y las directrices de paisaje a las que este documento se había comprometido, según se recoge en el siguiente diagrama.

El hecho de que tales directrices se hayan planteado en paralelo y de forma coordinada con la elaboración del PGM ha constituido una oportunidad muy interesante, pues, como señala el Convenio, sin perjuicio de que la política de paisaje pueda y deba plantearse desde diversos niveles (estatal, regional, local) y 
Figura 4. Diagrama del Estudio y Directrices del Paisaje de Trujillo

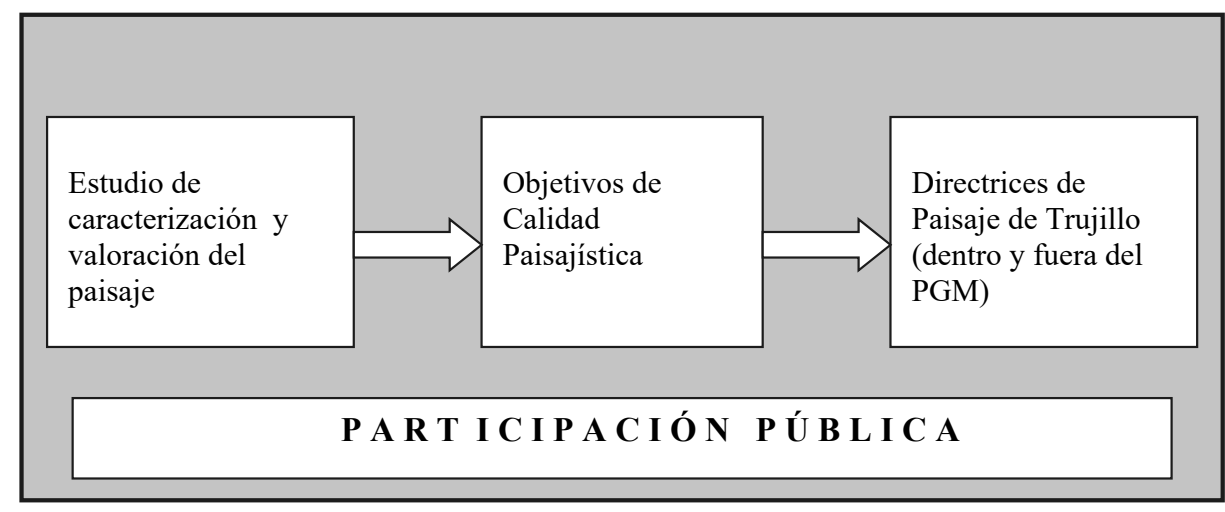

Elaboración propia

ámbitos de la administración pública (espacios protegidos, patrimonio cultural, turismo, desarrollo rural, etc.), se considera que las iniciativas a favor de la defensa y gestión de los valores del paisaje corresponden prioritariamente a las políticas urbanística y de ordenación territorial, y a los planes e instrumentos que las desarrollan (Zoido Naranjo, 2002; Mata Olmo, 2007).

Lo importante es que el programa de acción a favor del paisaje se incorpore al núcleo del plan, al diseño del «modelo territorial», es decir, al proyecto estratégico a medio y largo plazo de un territorio de calidad, más y mejor cohesionado. Para eso, una opción utilizada en España en los últimos años -siguiendo en parte la experiencia italiana- está siendo la elaboración de planes específicos de paisaje o, como en Cataluña, que dispone desde 2005 de Ley de protección, gestión y ordenación del paisaje, de las denominadas «Directrices de paisaje», que se integran preceptivamente en los instrumentos de planificación territorial de escala subregional (Esteban, 2010).

Otra opción, cuando no se cuenta con legislación específica, como en el caso de Extremadura, pero sí con voluntad política y con un marco normativo en urbanismo y ordenación del territorio que reconoce los valores paisajísticos, consiste en introducir el paisaje en la elaboración y desarrollo del propio Plan. Así se ha hecho en el caso de Trujillo. En este sentido, el PGM asume, dentro de su ámbito competencial y de sus determinaciones, una parte de las recomendaciones planteadas por la Estrategia, estableciendo las bases de un modelo territorial capaz de garantizar la sostenibilidad del paisaje y la mejora y fortalecimiento de algunas áreas degradadas o merecedoras de especial atención por la singularidad de sus valores. 
No obstante, además de estos aspectos fundamentales, que competen al instrumento de planificación local, han de implementarse otras acciones a favor del paisaje, tanto de protección sectorial, como de gestión y activación patrimonial y económica, que corresponden a distintos ramos de la administración autonómica y municipal, siempre teniendo en cuenta, de acuerdo con el CEP, que el paisaje es una realidad evolutiva y dinámica, y que el objetivo prioritario de todas las intervenciones es que el paisaje -cada paisaje-, pueda asumir los cambios lógicos de un territorio y una sociedad en permanente evolución, sin perder los rasgos y valores esenciales de su carácter.

En este texto solo es posible mencionar los seis grandes objetivos paisajísticos y las dieciocho directrices que los desarrollan, pero no así las acciones que concretan la Estrategia. No obstante, en el cuadro 2 se indica el número de acciones que corresponden a cada directriz y cuántas de ellas, en todo o en parte, se han incorporado ya a la Memoria y Normativa del PGM de Trujillo. Como podrá comprobarse, escapan al Plan aquellas directrices y acciones orientadas a la activación del patrimonio paisajístico y al fomento de actividades, concretamente agropecuarias de calidad y proximidad, dirigidas a vitalizar determinados paisajes, en concreto las huertas del berrocal trujillano. Tampoco forman parte del cuerpo normativo del Plan las acciones conducentes a la mejora paisajística de los accesos a Trujillo y a la mitigación de los impactos de la red eléctrica de alta tensión (se propone una acción conveniada con Red Eléctrica Española), así como determinadas acciones enfocadas a la administración de patrimonio histórico-cultural (autonómica y nacional) - un proyecto específico para la recuperación, ordenación y adecuación del uso público del recinto amurallado de Trujillo y su entorno, y otro para la declaración de BIC y la ordenación de la Albuera de San Jorge y entorno-.

Cuadro 2. Objetivos de calidad y directrices paisajísticas del «Estudio y Estrategia de Paisaje de Trujillo y su Tierra»

OBJETIVO DE CALIDAD PAISAJÍSTICA 1.

Protección y gestión del mosaico paisajístico del municipio de Trujillo y su Tierra

- Directriz 1.1. (dos acciones)

Integrar la salvaguarda de los valores del paisaje de Trujillo y su Tierra en la planificación territorial regional y subregional

- Directriz 1.2. (tres acciones, incluidas en normativa PGM)

Considerar el carácter y los valores del paisaje de Trujillo en la definición de las bases ambientales y culturales del modelo territorial del Plan General Municipal (PGM)

Directriz 1.3. (dos acciones, incluidas en normativa PGM)

Gestionar las actividades y los usos del suelo en terrenos no urbanizables de acuerdo con los valores y las dinámicas del paisaje 
OBJETIVO DE CALIDAD PAISAJÍSTICA 2.

Protección, mejora y activación patrimonial del paisaje del Berrocal de Trujillo

- Directriz 2.1. (dos acciones, incluidas en normativa PGM)

Garantizar y fortalecer la protección de los terrenos rústicos del Berrocal a través del PGM

- Directriz 2.2. (dos acciones, incluidas en normativa PGM)

Promover un modelo de ciudad respetuosa, integrada y enaltecedora de los valores del paisaje del Berrocal, del que forma parte indisociable

- Directriz 2.3. (tres acciones, dos de ellas incluidas en normativa PGM)

Salvaguardar y fomentar el valor patrimonial de los arrabales, de sus huertas y cercas en el paisaje del Berrocal trujillano

- Directriz 2.4 (dos acciones, una de ellas incluidas en normativa PGM: Plan Especial para conjunto de la Albuera de San Jorge)

Proteger, recualificar y activar elementos y conjuntos de alto valor patrimonial y

paisajístico en el Berrocal

- Directriz 2.5. (una acción)

Adopción de una figura específica de protección para el Berrocal trujillano, integradora de los valores naturales y culturales del paisaje

OBJETIVO DE CALIDAD PAISAJÍSTICA 3.

Fortalecer la protección de los componentes y valores ecológicos del paisaje, en especial los ligados al agua

- Directriz 3.1. (una acción)

Establecimiento de figuras específicas de protección para paisajes y estructuras paisajísticas de alto valor intrínseco y conectividad ecológica

- Directriz 3.2. (dos acciones)

Impulso a la protección, gestión y uso público, con las cautelas precisas, de los elementos y estructuras hídricas del paisaje

OBJETIVO DE CALIDAD PAISAJÍSTICA 4.

Promover actividades agropecuarias tradicionales, innovación y reactivación económica ligadas a los valores del paisaje

- Directriz 4.1. (tres acciones)

Apoyo local y regional a la producción agrícola de calidad y proximidad en los huertos del Berrocal

- Directriz 4.2. (cuatro acciones)

Fortalecimiento y ampliación de las iniciativas de apoyo a prácticas agropecuarias sostenibles ligadas al paisaje en dehesas, pastizales y labrados

- Directriz 4.3. (dos acciones) Incorporación de la diversidad paisajística a la imagen y a otros recursos del destino turístico «Trujillo y su Tierra, paisajes de Extremadura».

OBJETIVO DE CALIDAD PAISAJÍSTICA 5.

Fomentar el acceso público al paisaje para su interpretación y disfrute

- Directriz 5.1. (una acción, incluida en normativa del PGM) Creación una red de miradores de alto contenido panorámico y capacidad de visión y lectura de la diversidad paisajística de Trujillo y su Tierra

- Directriz 5.2. (dos acciones, incluidas en normativa del PGM) Creación de una red de itinerarios paisajísticos para el acceso y la contemplación del mosaico de tipos de paisaje y elementos patrimoniales, naturales y culturales, de Trujillo y su Tierra

- Directriz 5.3.

Centro de Interpretación de naturaleza y paisaje y avistamiento de aves en el Berrocal trujillano 


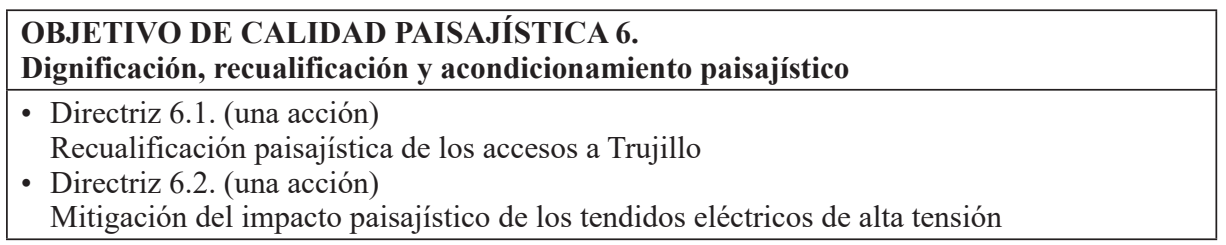

A MODO DE EPÍLOGO: LA CONSIDERACIÓN DE LOS VALORES DEL PAISAJE EN LA CLASIFICACIÓN DEL SUELO NO URBANIZABLE Y EN LA DEFINICIÓN DEL MODELO DE CIUDAD

El «Estudio y Estrategia del paisaje de Trujillo», que -no se olvide- figura como anexo del Plan, contiene, como se ha dicho, un análisis detallado de la diversidad paisajística del término municipal de Trujillo y de algunos otros municipios de su histórica Tierra. Las piezas resultantes de los estudios de caracterización y valoración del paisaje no tienen por qué ser $-\mathrm{o}$ al menos, no siempre- unidades de ordenación y gestión urbanística en los términos que establece la legislación de suelo y ordenación del territorio.

Ahora bien, en el caso de Trujillo, por la escala de detalle a la que se ha trabajado y por las propias características de sus paisajes - con altos niveles de homogeneidad morfológica, funcional, perceptiva y de conservación-, ha resultado posible establecer una correspondencia estrecha entre unidades o tipos de paisaje (según los casos) y categorías de clasificación de suelos no urbanizables, en especial de los protegidos (SNUP) (cuadro 3). Esa correspondencia no impide que determinados elementos o estructuras paisajísticas cuenten de antemano con valores reconocidos y tutelados por legislación sectorial de protección (espacios naturales protegidos, patrimonio histórico-cultural, vías pecuarias, dominio público hidráulico, etc.), tutela que se incorpora lógicamente a la propuesta de ordenación conforme a lo establecido por la legislación urbanística.

La contribución novedosa del Plan en la tarea clasificadora ha consistido en la fundamentación paisajística de una superficie considerable de suelos no urbanizables protegidos del término municipal, más allá de los que ya vienen protegidos por normas sectoriales. Para ello, partiendo de la caracterización y valoración de unidades y tipos de paisaje, se han establecido correspondencias con las categorías de SNUP que el Plan establece, de acuerdo con el artículo 11 de la Ley 15/2001, de 14 de diciembre, del Suelo y Ordenación Territorial de Extremadura. En la tabla final se recogen tales correspondencias, cuya justificación no es posible recoger en estas páginas por falta de espacio.

Igualmente, la caracterización del paisaje, que incluye el estudio de tendencias y cambios observados, y de problemas y amenazas que gravitan sobre algunos paisajes, ha servido también de base para regular los usos del suelo, diferenciando (i) los que son vocacionales de cada paisaje y, por tanto, admisibles sin limitación alguna, (ii) los que por resultar lesivos de tales valores 
deben ser prohibidos, y (iii) una gama de usos y aprovechamientos que pueden admitirse sujetos a determinadas limitaciones, establecidas bien por legislación sectorial o por requerimientos del propio PGM.

Por su parte, los terrenos clasificados como Suelo No Urbanizable Común (SNUC) comparten las características y, en general, los mismos valores de las unidades y tipos de paisaje de las que forman parte. Conceptualmente, el establecimiento de estos suelos por el PGM no responde necesariamente a una menor presencia de valores, sino a razones de localización y oportunidad. No obstante, se ha evitado que, en lo posible, contengan elementos o estructuras de especial interés paisajístico, natural o cultural.

En cualquier caso, desde la perspectiva de la política de paisaje del Convenio de Florencia, la clasificación como SNUC no implica falta de acción paisajística en ese tipo de suelo. Muy al contrario. En razón de su estado de deterioro, de su relación escénica y perceptiva con el conjunto monumental de Trujillo, o de las calificaciones de las que podrán ser objeto, el no urbanizable común necesita también atención paisajística, en unos casos con medidas de recualificación y mejora, y en otros, de integración de edificaciones y actividades en el paisaje, conforme a lo que establece la Ley 16/2015, de 23 de abril, de protección ambiental de la Comunidad Autónoma de Extremadura, que remite expresamente al Convenio Europeo del Paisaje. Todo ello sin perjuicio de lo que al respecto se pueda establecer en el PGM.

Cuadro 3. Correspondencia entre los tipos de paisaje y la clasificación del Suelos No Urbanizables Protegidos del PGM de Trujillo

\begin{tabular}{|l|l|}
\hline TIPOS DE PAISAJE & CATEGORIAS SNUP EN EL PGM DE TRUJILLO \\
\hline 1. Huertas del Berrocal de Trujillo & $\begin{array}{l}\text { SNUP-Protección Paisajística de las Huertas del } \\
\text { Berrocal de Trujillo }\end{array}$ \\
\hline 2. Berrocales de la Tierra de Trujillo & $\begin{array}{l}\text { SNUP-Protección Paisajística de los Berrocales de la } \\
\text { Tierra de Trujillo }\end{array}$ \\
\hline 4. Llanos del noroeste de Trujillo & $\begin{array}{l}\text { SNUP-Protección Estructural Agropecuaria de los } \\
\text { Llanos del noroeste de Trujillo }\end{array}$ \\
\hline 5. Dehesas trujillanas & $\begin{array}{l}\text { SNUP-Protección Estructural Agropecuaria y Forestal } \\
\text { de Dehesas }\end{array}$ \\
\hline $\begin{array}{l}\text { 6. Montes y dehesas de las } \\
\text { vertientes del Almonte y el Tamuja }\end{array}$ & $\begin{array}{l}\text { SNUP-Protección Natural de los Montes y Dehesas de } \\
\text { las vertientes del Almonte y el Tamuja (*) }\end{array}$ \\
\hline $\begin{array}{l}\text { 7. Sierras Extremeñas. Sierra de los } \\
\text { Lagares }\end{array}$ & $\begin{array}{l}\text { SNUP-Protección Paisajística Sierras Extremeñas. } \\
\text { Sierra de los Lagares }\end{array}$ \\
\hline $\begin{array}{l}\text { 8. Pastizales y labrados del entorno } \\
\text { de los berrocales de Trujillo }\end{array}$ & $\begin{array}{l}\text { SNUP-Protección Estructural Agropecuaria de } \\
\text { Pastizales y Labrados del entorno de los Berrocales de } \\
\text { Trujillo }\end{array}$ \\
\hline 9. Riberos & SNUP-Protección Natural de Riberos \\
\hline $\begin{array}{l}\text { 11. Viñedos de la Dehesa de la } \\
\text { Torrecilla }\end{array}$ & $\begin{array}{l}\text { SNUP-Protección Estructural Agropecuaria de los } \\
\text { viñedos de la Torrecilla }\end{array}$ \\
\hline
\end{tabular}




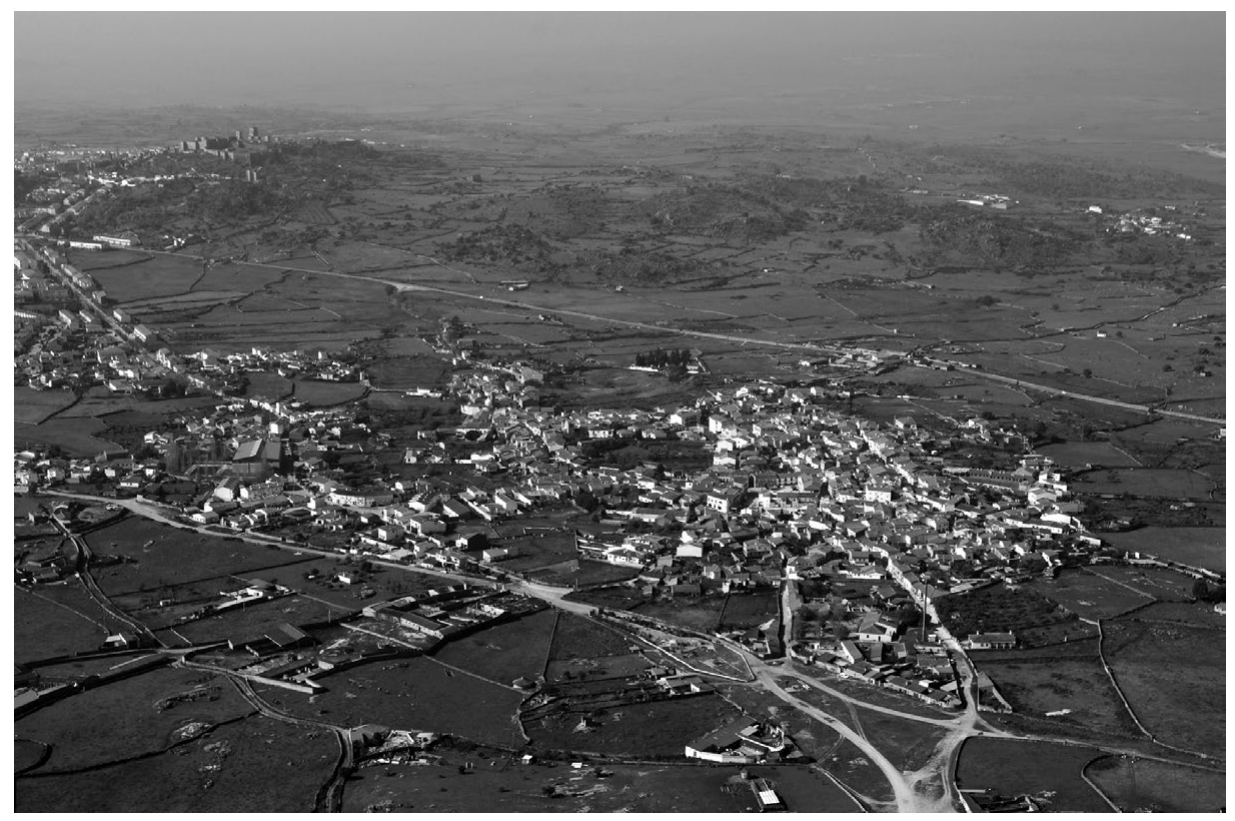

Figura 5. Vista aérea del Berrocal entre Huerta de Ánimas y Trujillo al fondo, mostrando el «vacío» entre la ciudad y la aldea, objeto de especial cuidado paisajístico por el PGM.

Pero tan importante, o más aún, que la consideración del paisaje en el tratamiento del suelo no urbanizable, es la definición del modelo de crecimiento de ciudad. De una ciudad monumental, paisajística por su configuración y por la fuerte relación visual y coevolutiva con su entrono, que, pese a sus modestas dimensiones, ha estado sujeta, a su escala y como tantas otras ciudades, a procesos de banalización y deterioro de su periferia y a expectativas de crecimiento injustificadas para su tamaño y muy lesivas de los valores paisajísticos en juego.

Por eso, el PGM, atendiendo a las directrices del Estudio y Estrategia de paisaje, ha optado por un modelo de ciudad respetuosa, integrada y enaltecedora de los valores del paisaje del Berrocal, del que forma parte indisociable. El Plan asume una propuesta de reducido crecimiento urbano, incidiendo en los aspectos de ordenación interior, eficiencia urbanística, evitación de la dispersión urbana e industrial, e integración paisajística de los nuevos desarrollos.

En particular, actúa con especial cuidado en la ordenación de los suelos urbanizables entre Trujillo y el núcleo de Huerta de Ánimas, al norte, sobre uno de los vacíos urbanos más interesantes del Berrocal en el entorno de la ciudad, evitando la urbanización extensiva y concentrando la edificación junto al tejido urbano existente a lo largo de la Avenida Reina Cristina (figura 5). Así mismo, pretende consolidar, con las mejoras y adaptaciones imprescindibles, la 
estructura tradicional de los arrabales o pedanías del Berrocal (Belén, Huertas de Ánimas y Huertas de la Magdalena), manteniendo sus límites y morfología urbana tradicionales, evitando la aparición de nuevas manzanas, aumentos significativos de densidad y aperturas de nuevos viales.

Actuando así, el PGM establece las bases para garantizar el carácter del conjunto paisajístico -visual, estético, histórico y funcional- que han construido durante siglos Trujillo, su Berrocal y su Tierra. El Plan llega hasta donde puede llegar, pero el Estudio y la Estrategia del paisaje abren un camino de más alcance estratégico, educativo y civilizador para el que la implicación ciudadana constituye una llave fundamental.

\section{BiBLIOGRAFÍA CITADA}

Alvarado Corrales, E. (2013): «El Berrocal de Trujillo, un paisaje natural y cultural diferenciado». Actas del XIII Congreso de Geógrafos Españoles. Asociación de Geógrafos Españoles, Palma de Mallorca, pp. 21-31.

BRunet-VIncK, V. (2004): Méthode pour des Atlas de paysages. Enseignements méthodologiques de 10 ans de travaux. Ministère de l'Environnement et le Développement durable, Paris, 2004, 127 pp.

CAMPESINo FernándeZ, A.J. (1991): «El medio ambiente en el planeamiento urbano y municipal: Trujillo, ciudad y territorio», en Revista del Seminario de Estudios Cacereños, núm. 22, pp. 439-449.

English Heritage (2008 y 2011): Seeing the History in the View: A Method for Assessing Heritage Significance within Views. English Heritage, London, $61 \mathrm{pp}$.

Esteban, J. (2010): «Les directrius del paisatge», en NEL-LO, O. (dir.): La política de paisatge a Catalunya. Generalitat de Catalunya. Departament de Politica Territorial I Obres Públiques, Barcelona, pp. 56-67.

GEA21 SL (2014): Repensar el paisaje de Trujillo. Ayto. de Trujillo, Fundación Reale, Fundación Xavier de Salas, s/p.

Ibanez, R.; Merlot, Th.; Roux, A. (2013): La Recommandation UNESCO sur les Paysages Urbains Historiques. Polytech, Tours, $84 \mathrm{pp}$.

LALANA Soto, J.L. (2011): «El paisaje urbano histórico : modas, paradigmas y olvidos», en Ciudades, 14 (1), pp. 15-38.

Maldonado Escribano, J. (2006): «Palacios, cortijos y casas de campo en las dehesas de Trujillo (Cáceres) desde el siglo XV al VIX», en XXXV Coloquios Históricos de Extremadura. Trujillo, pp. 379-412.

Mata Olmo, R. (2007): «Paisaje y territorio. Un desafío teórico y práctico», en SÁNCHEZ Pérez-Moneo, L. y Troitiño, M.A. (coords.), Agua, territorio y paisaje. De los instrumentos programados a la planificación aplicada. V Congreso Internacional de Ordenación del territorio. FUNDICOT, Madrid, pp. 243-282.

Mata Olmo, R. (2008): «El paisaje, patrimonio y recurso de desarrollo territorial sostenible. Conocimiento y acción pública», en Arbor. Ciencia, Pensamiento y Cultura, CLXXXIV: 729, pp. 155-172. 
Mata Olmo, R. (2010): Patrimonio paisajístico. Valle del Nansa y Peñarrubia (Cantabria). Fundación Marcelino Botín, Santander, 145 pp.

MecD-Ipce (2012): Plan Nacional de Paisaje Cultural. Ministerio de Educación, Cultura y Deporte-Instituto de Patrimonio Cultural de España, Madrid.

Meer Lecha-Marzo, A. de (coord.) (2010): Valoración del patrimonio territorial y paisajístico. Valle del Nansa y Peñarrubia (Cantabria). Fundación Marcelino Botín, Santander, 2010.

Nogué, J. y SAla, P. (2006): Prototipus de catàleg de paisatge. Bases conceptuals, metodológiques y procedimentals per elaborar els catàlegs de paisatge de Catalunya. Observatori del Paisatge, Olot y Barcelona 2006, 97 pp.

Pardo García, S.M. (2010): «Aproximación metodológica a las vistas de los núcleos de población»: el caso de Vélez-Málaga», en Cuadernos Geográficos, 46, pp. 35-63.

PARDo GARCíA, S.M. (2015): Las vistas panorámicas de núcleos urbanos: propuesta para su análisis y aplicación al caso de Andalucía. Tesis doctoral (inédita), Universidad de Málaga, 2 vols.

Pardo García, S. M.; Mérida Rodríguez, M. (2015): «A geoespatial indicator for assessing urban panoramics views», en Computers, Environment and Urban Systems, 49, pp. 42-53.

Prieur, M. et Durousseau, S. (2004): «Étude de droit comparé sur la participation du public en matière de paysage dans le contexte de la mise en œuvre de la Convention Européenne du Paysage». Strasbourg, Conseil de l'Europe, T-FLOR 3 (2004) 6, 47 pp.

Quirós LiNARES, F. (2005): «El paisaje urbano en la geografía española moderna», en Ortega Cantero, N. (ed.): Naturaleza y cultura del paisaje. Fundación Duques de Soria y Universidad Autónoma de Madrid, Madrid, pp. 171-186.

Rubio Garlito, M. ${ }^{a}$ A. (1986): «Sistema de propiedad y tipo de parcelado en Trujillo durante la segunda mitad del siglo XIX». Coloquios Históricos de Extremadura, 5 pp.

SÁnchez Marroyo, F. (1993): Dehesas y terratenientes en Extremadura. La propiedad de la tierra en la provincia de Cáceres en los siglos XIX y XX. Asamblea de Extremadura, Mérida, $483 \mathrm{pp}$.

Sánchez Rubio, M. A. (1993): El Concejo de Trujillo y su Alfoz en el tránsito de la Edad Media a la Edad Moderna. Servicio de Publicaciones de la Universidad de Extremadura, Badajoz, 479 pp.

SCOTTISH NATURAL HERITAGE-THE COUNTRYSIDE AGENCY (en la actualidad, English Nature)(2002, version de 2014): Landscape Character Assessment. Guidance for England and Scotland. The Coutryside Agency, Cheltelham, 86 pp.

Troitiño Vinuesa, M.A. y Troitiño Torralba, L. (2011): «Estudio sobre la funcionalidad turística del municipio de Carmona y estrategias de actuación», en Revista ph. Instituto Andaluz del Patrimonio Histórico, n. ${ }^{\circ}$ 78, pp. 4-13.

UNESCO (2011): «Recomendación sobre el paisaje urbano histórico». Actas de la Conferencia General, 36. ${ }^{a}$ Reunión. París (versión en español).

Venegas Moreno, C. y Rodríguez Rodríguez, J. (2002): «Valoración de los paisajes monumentales. Una propuesta metodológica para la integración paisajística de los 
conjuntos históricos», en Paisaje y Ordenación del Territorio. Consejería de Obras Públicas y Transportes, Junta de Andalucía-Fundación Duques de Soria, Sevilla, pp. 153 a 165 .

Venturi Ferriolo, M. (1999): Estética del Paesaggio. Guerini, Milano, 1999.

VV.AA. (2010): Marco conceptual y metodológico para los paisajes españoles. Aplicación a tres escalas. Junta de Andalucía, Consejería de Obras Públicas, Sevilla, pp.467.

Zoido Naranjo, F. (2002): «El paisaje y su utilidad para la ordenación del territorio», en Paisaje y Ordenación del Territorio. Consejería de Obras Públicas y Transportes, Junta de Andalucía-Fundación Duques de Soria, Sevilla, pp. 21-32.

Zoido Naranjo, F. (2012): «Paisaje urbano. Aportaciones para La definición de un marco teórico, conceptual y metodológico», en Delgado, C., JUARISTI, J. y TOMÉ, S. (eds.): Ciudades y paisajes urbanos en el siglo XXI. Ediciones de Librería Estudio, Santander, pp. 13-91.

ZoIdo Naranjo, F. (2013): Identificación, caracterización y cualificación de recursos paisajísticos en el entorno del núcleo urbano de Constantina (Andalucía, España). Pays Med Urban-Junta de Andalucía-Centro de Estudios Paisaje y Territorio, 245 pp.

Proyecto I+D+I CSO2012 39564-CO7-03, Paisajes Patrimoniales de España 